Part of Journal of Research of the National Bureau of Standards, Volume 27, October 1941

\title{
EFFECTS OF HYDROCHLORIC ACID AND SALTS ON THE ABSORPTION OF LIGHT BY $\beta$-NAPHTHOQUINONESUL- FONIC ACID
}

\author{
By Baker Wingfield and S. F. Acree
}

\section{ABSTRACT}

In order to evaluate the effects of hydrochloric acid and neutral salts on the absorption of light by an organic acid dye, spectrophotometric measurements were made of a series of solutions of hydrochloric acid and of neutral salts plus hydrochloric acid, each containing $3 \times 10^{-4} M \beta$-naphthoquinonesulfonic acid.

The dye in these solutions showed small differences in spectral absorption. Similar differences may contribute to the changes of absorption shown by true indicators. Most of the data were compatible with the assumption that new absorption bands were not produced or that there was no considerable shift in the position of the original bands with respect to wave number.

The increase in the absorption by the dye in the presence of salts was proportional to the square root of the molar activity of the electrolyte. The proportionality factor was different for each salt and varied from 0.144 to 0.353 .

The results suggest that the specific effects of ions on the absorption indices of positive, neutral, and negative forms of an indicator must be taken into account, as well as the normal effects of the ions on the dissociation of the indicator, for accurate $\mathrm{pH}$ measurements.

\section{CONTENTS}

Page

I. Introduction

II. Equipment and chemicals

III. Experimental procedure

IV. Discussion

V. Conclusions

VI. References

\section{INTRODUCTION}

It is well known that intense color changes are produced by the addition of acids or bases to solutions containing organic compounds of certain classes. The color change is associated with the ionization (or suppression of ionization) of one of the acidic or basic groups of these compounds. The spectral absorption is different for their ion and mole forms. Because the relative proportion of ion and mole forms changes with the hydrogen-ion concentration, these compounds are used in $\mathrm{pH}$ measurements.

The use of the indicator method ${ }^{1}$ for $\mathrm{pH}$ measurements presupposes the validity of a generalized mass law equation for the reaction of hydrogen ions with the indicator itself. For a monovalent acid indicator the equation is

$$
\mathrm{K}=\frac{\left[\mathrm{H}^{+}\right]\left[\mathrm{In}^{-}\right] f_{\mathrm{H}}{ }^{+} f_{\mathrm{In}^{-}}}{[\mathrm{HIn}] f_{\mathrm{HIn}}}
$$

1 See references $[1,2,4,5,9,14,19,21,24$, and 27$]$ for reviews of the theories of indicators and the mass law applications in pH measurements. 
where $\left[\mathrm{H}^{+}\right],\left[\mathrm{In}^{-}\right]$, and $[H I n]$ are the concentrations of hydrogen ion, indicator anion, and undissociated indicator, respectively, $f_{\mathrm{H}^{+}}{ }^{+}, f_{\mathrm{In}}{ }^{-}$, and $f_{\text {HIn }}$ are the respective activity coefficients of these components, and $K$ is the ionization constant. It is presumed that $K\left(f_{\mathrm{HIn}} / f_{\mathrm{In}^{-}}\right)$has been determined. The ratio $\mathrm{In}^{-} / \mathrm{HIn}$ which then determines $\left[\mathrm{H}^{+}\right] f_{\mathbf{H}^{+}}{ }^{+}$ is estimated by matching a solution containing a mixture of the two forms against two solutions containing known amounts of the ion and mole forms, respectively.

Changes in the absorption of light by either or both forms of the indicator which may be caused by different environments, such as

\section{A. BETA-NAPHTHOQUINONE SULFONIC ACID.}<smiles>O=C(O)c1cc(S(=O)(=O)O)ccc1O</smiles><smiles></smiles>

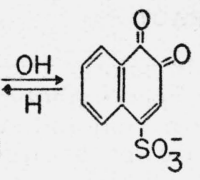

OXONIUM FORM surrounding electric fields $[1,25]^{2}$ from electrolytes, are thus excluded from consideration. Such changes in light absorption, if they exist, will affect the color and may lead to incorrect estimates of $\mathrm{pH}$. These optical effects by salts will be termed "specific salt effects" to differentiate them from the normal effect of salts on the activity coefficients of the indicator acid.

It is easier to estimate the

\section{B. SULFONPHTHALEINS}

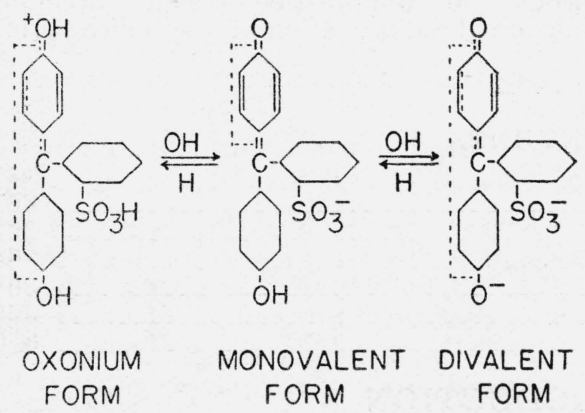

FIgURE 1.-Various forms of $\beta$-naphthoquinonesulfonic acid and sulfonephthaleins.

yellow color of a sulfonephthalein free acid. magnitude of specific salt effects on the different colored forms of indicators, if work is begun with a substance related in its chemical structure to many of the useful indicators, but which is not an indicator itself and therefore does not exhibit intense color changes with ionization. Such a substance is found in $\beta$-naphthoquinonesulfonic acid, which contains a quinone chromophore and a sulfonate group and possesses the typical

The purpose of this work is therefore to determine how the addition of salts or the further additions of acid to acid solutions of $\beta$-naphthoquinonesulfonic acid affects the molar absorption indices ${ }^{3}$ of this compound.

\footnotetext{
2 Figures in brackets indicate the literature references at the end of this paper.

3 The molar absorption index, $k$, which will be referred to in the remainder of the paper as molar index, is $\log (100 / t)$, where $t$ is the calculated transmittancy in percent when the concentration of the absorbing ma. terial is 1 mole per liter and the length of the absorbing path is $1 \mathrm{~cm}$. This is a constant for a particular substance and wavelength, provided Beer's law holds. The molar absorption index is obtained from actual transmittancy data from the expression $[\log (100 / T] / c l$, where $T$ is the measured transmittancy in percent, $c$ is the concentration of the dye in moles per liter, and $l$ is the length in centimeters. In calculations involving both the concentration and the absorption, it is necessary to use the molar absorption index.
} 


\section{EQUIPMENT AND CHEMICALS}

A Keuffel and Esser visual spectrophotometer, modified with variable slits in both eyepiece and collimator ends, was used for the preliminary investigations on solutions of $\beta$-naphthoquinonesulfonic acid. A General Electric recording spectrophotometer of the Hardy type, which has been discussed by Hardy [10] and Michaelson [18], was used to secure the precision curves of the transmittancies of the various dye solutions. This instrument was fitted with slits of a width which transmitted a spectrum region of approximately $4 \mathrm{~m} \mu$. The recorded transmittancies, which covered the spectral region from 400 to $750 \mathrm{~m} \mu$, could be read to 0.1 percent of full scale. A few measurements were made with a Coleman photoelectric spectrophotometer fitted with slits of a width which transmitted a spectrum region of approximately $5 \mathrm{~m} \mu$. The transmittancies could be measured from 350 to $1,000 \mathrm{~m} \mu$ with this instrument and were read to 0.1 percent.

The pair of transmission cells used with the Keuffel \& Esser and the General Electric recording instrument were constructed of Pyrex glass. The ends of glass tubing, $2.5 \mathrm{~cm}$ in diameter, were ground and polished to give a length of $2.000 \mathrm{~cm}$. Cells of $5-\mathrm{cm}$ length were also used. Circular disks of selected Pyrex glass, slightly larger in diameter than the tubing, were ground and polished to a uniform thickness of approximately $2 \mathrm{~mm}$. These disks were then fused to the ends of the prepared tubes. A glass side tube had been previously sealed into the glass tubes for filling and emptying the cells. The Coleman spectrophotometer was supplied with two matched glass cells having plain, parallel walls which interposed a liquid column of approximately $1.3 \mathrm{~cm}$ in the light path.

Commercially prepared sodium $\beta$-naphthoquinonesulfonate was repurified once by the method of Folin [7], and was stored in lightproof bottles under anhydrous conditions. The dye, dissolved in water, fades slowly when it is exposed to strong light. In acid solutions, however, the dye proved sufficiently stable for spectrophotometric measurements. Tests showed that no fading could be observed in the presence of $0.005 \mathrm{M} \mathrm{HCl}$ during the time elapsing between the preparation of the solution and the measurement of the transmittancy in the visible spectrum. A stock solution of the dye in $0.05 \mathrm{M} \mathrm{HCl}$ was prepared and allowed to stand in dim light. Samples taken from this solution immediately after preparation, and at various intervals up to 6 hours, were diluted to $0.005 \mathrm{M} \mathrm{HCl}$. The transmittancy values for these solutions did not differ from one another in excess of the experimental error. In alkaline solutions the dye deteriorates, as shown by a darkening of its color. To determine whether a slow change takes place in acid solutions similar to that occurring in basic solutions (but visible only in alkaline solutions), transmittancy measurements were made on solutions of the dye prepared from the above stock acid solution after adjusting it to $\mathrm{pH} 8$. The transmittancy measurements indicated that the acid stock solution had not suffered any appreciable deterioration in 6 hours. Definite changes in the absorption by the dye occurred during 24 hours in both the acidic and basic solutions.

The dye solutions were prepared for transmittancy measurements in the following manner: $78.1 \pm 0.1 \mathrm{mg}$ of the solid sodium $\beta$-naph- 
thoquinone sulfonate was dissolved in $25 \mathrm{ml}$ of $0.2 \mathrm{M} \mathrm{HCl}$ and diluted at once to $100 \mathrm{ml}$. This solution was freshly prepared for each day's run. A $10-\mathrm{ml}$ portion of the concentrated dye solution was then transferred to a 100-ml volumetric flask, the desired amount of concentrated salt solution added, and the solution diluted to the mark. The final solution was then $0.0003 M$ in the dye, $0.0003 M$ in sodium ion, and $0.005 \mathrm{M}$ in $\mathrm{HCl}$, plus the salt. This procedure was followed for $\mathrm{KCl}, \mathrm{Li}_{2} \mathrm{SO}_{4}$, and $\mathrm{CaCl}_{2}$. In the solutions in which $\mathrm{HCl}$ was present alone, sufficient acid was added to obtain the desired concentration. In the preparation of the $\mathrm{AlCl}_{3}$ solutions, the final concentration of $\mathrm{HCl}$ was adjusted to $0.15 \mathrm{M}$ to prevent hydrolysis of the salt. At the same time that the dye solutions were prepared for use in one cell, solutions for the companion cell were made in which the dye was omitted but which were identical in regard to the other components. The recorded transmittancies were dependent upon the dye alone, since any absorption or reflection by the salt, acid, or glass was balanced by a similar loss in the other cell. The solutions were prepared and the measurements made at room temperature, about $20^{\circ}$ to $25^{\circ} \mathrm{C}$.

The salts used were chemically pure grades. The only treatment given them was a filtration of the concentrated solutions.

\section{EXPERIMENTAL PROCEDURE}

The portion of the single absorption band used in the following computations extended from wave numbers ${ }^{4}$ of about 20,000 to 23,260 (500 to $430 \mathrm{~m} \mu$ ). Figure 2 is typical of the spectrophotometric data. The ordinates of the recorded curves were read at $10-\mathrm{m} \mu$ intervals and corrected to percentage transmittancy according to the methods outlined by Gibson and Keegan [8]. The accuracy of the transmittancy measurements was of the order of 0.5 percent of full scale. These transmittancies were used to calculate the molar indices. These indices were plotted against wave number. The smooth curves drawn through these points are shown in figures 3 to 6 . The curve for the $\mathrm{AlCl}_{3}$ solutions is omitted to conserve space.

The solid portions of the curves represent the more valuable part of the data; in the dotted portions, the data are less certain, because the values of the molar indices are too small to be useful (wave numbers 18 to $\left.20 \times 10^{3}\right)$ and the experimental transmittancy data are too unreliable (wave numbers 23 to $25 \times 10^{3}$ ).

Since the changes in the molar indices were to be used as measures of the effect of $\mathrm{HCl}$ and of the salts on the dye, the constancy of the ratio of the molar indices of any two curves at identical wavelengths was determined at intervals of $10 \mathrm{~m} \mu$. For concentrations of acid or salt up to $0.5 M$, the index ratios for any two curves ${ }^{5}$ were found to be constant within the experimental error. At salt or acid concentrations of 1 or $2 M$, the ratios showed inconsistencies which were equivalent to transmittancy variations of 0.6 to 1.4 percent. For the dye in $\mathrm{CaCl}_{2}$ solutions, inconsistencies in the ratios of individual curves to the $0.005 \mathrm{M} \mathrm{HCl}$ curve varied from values equivalent to 0.8 percent

4 "Wave number" in this paper is defined as the number of wavelengths in a centimeter.

5 In these calculations, each individual curve was compared with the curve for the dye in $0.005 \mathrm{M} \mathrm{HCl}$, so that all of the changes were related to the molar index values for the dye under these conditions. The average ratio for each curve compared with that for $0.005 \mathrm{M} \mathrm{HCl}$ increased with increase in concentration for each electrolyte. 
in transmittancy at $\mathrm{CaCl}_{2}$ concentrations of 0.005 and $0.1 \mathrm{M}$, to 6 percent at $2 M$.

The constancy of the ratios of the molar indices between any two curves at identical wave numbers up to $0.5 \mathrm{M}$ electrolyte, the absence of any considerable shift in the band with respect to wave number,

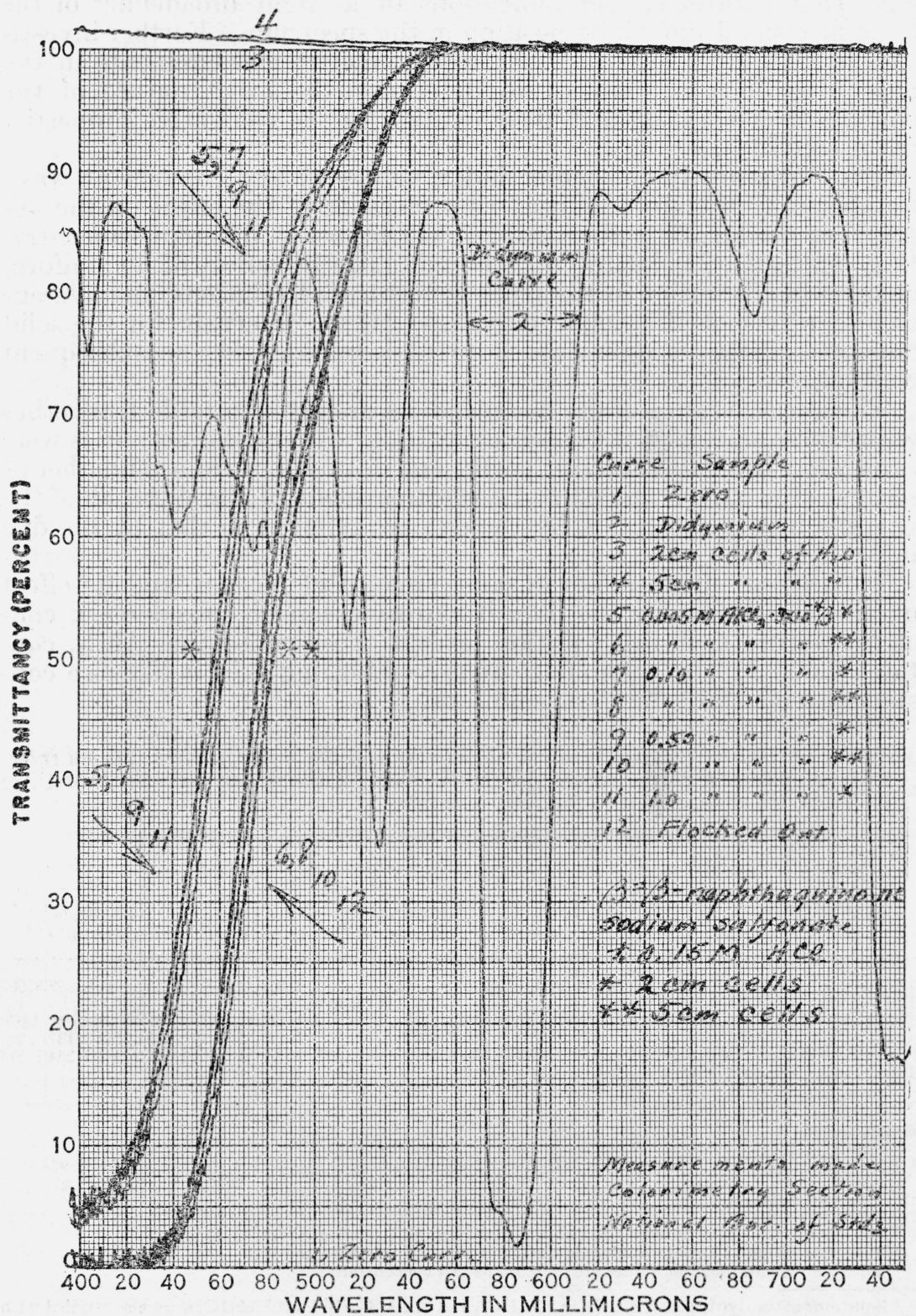

FIGURE 2.-Transmittancy of $0.0003 \quad M$-naphthoquinonesulfonic acid in 0.15

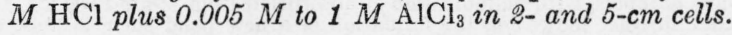

This is a facsimile of the laboratory record. 
and the apparent general increase in absorption at all wave numbers in the ultraviolet ${ }^{6}$ and visible with increased concentration of electrolyte, indicate that the effect of electrolytes on the absorption band (peak 26,500 wave number) is mainly a uniform increase in index at all wave numbers. There is, however, some flattening at the peak for high concentrations, and indications of a slight broadening of the band or a small shift in its position in the spectrum. Further investigation with more accurate spectrophotometric measurements in the near ultraviolet is required to determine the exact nature of the changes in absorption and their relation to the colligative properties of the solutions.

The variation in the molar index values at any convenient wave number may therefore be used as a measure of the effect on the absorption produced by the various electrolytes at different concentrations up to $0.5 M$ electrolyte. To minimize the effect of nonuniform changes in absorption in the more concentrated solutions, the average of the ratios of the molar indices, at $10 \mathrm{~m} \mu$ intervals, for the solid portions of the curves (figs. 3 to 6 ) were used in the subsequent correlations.

The average ratios of the molar indices are given in table 1 , together with molar activities of the salts and $\mathrm{HCl}$. The molar activities were calculated from the activity coefficient data taken from a number of sources $[11,12,17,22,23]$. In the treatment of the data, all of the changes in the absorption by the dye are referred to that by the dye in $0.005 \mathrm{M} \mathrm{HCl}$.

Each solution contains the same amount of $\mathrm{Na}$ ion, and its effect on the absorption by the dye, if additive, can be considered a constant. Since each salt solution, except those containing $\mathrm{AlCl}_{3}$, contains $0.005 M \mathrm{HCl}$, the effect of the stabilizing acid is likewise considered a constant for these solutions.

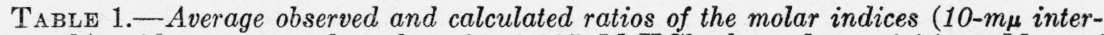
vals) with respect to the values for $0.005 M \mathrm{HCl}$, the molar activities, $M \pm$, of $\mathrm{HCl}$ and the salts, and the equation constants

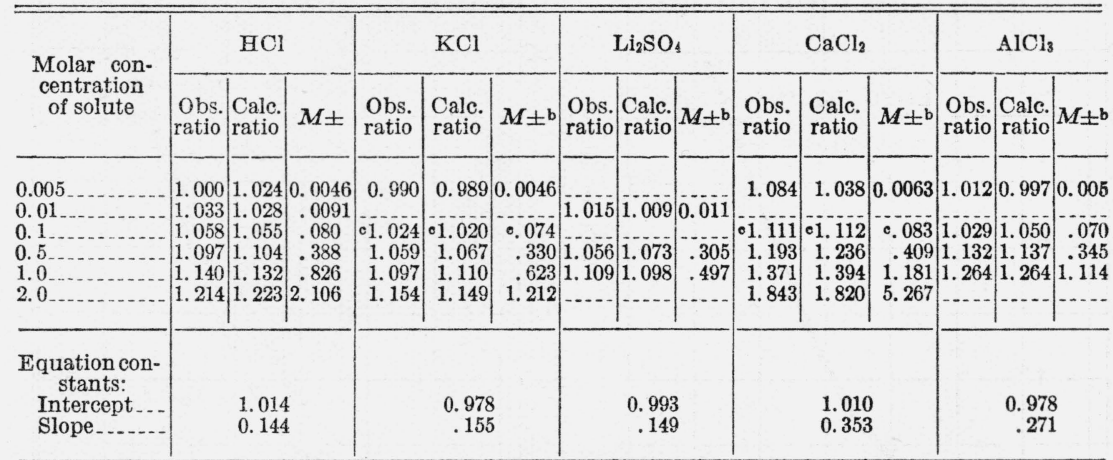

a The activity coefficients were interpolated from data in the literature $[11,12,17,22,23]$.

b These molar activities do not include the small amounts of stabilizing $\mathrm{HCl}$.

- These ratios and molar activities are for $0.095 \mathrm{M}$ salt concentration.

${ }^{6}$ Solutions of the dye in $0.005 \mathrm{MHCl}$, in $2 \mathrm{MHCl}$, and in $2 \mathrm{M} \mathrm{CaCl} 2+0.005 \mathrm{MHCl}$ were also studied with the Coleman regional spectrophotometer at 350 to $1,000 \mathrm{~m} \mu$ and with the type E1 Hilger spectrograph at 230 to $800 \mathrm{~m} \mu$. The dye gives three bands with peaks st approximately $26,500(377 \mathrm{~m} \mu), 35,000(286 \mathrm{~m} \mu)$, and $39,000(257 \mathrm{~m} \mu)$ wave numbers, with no indication of absorption from 550 to $1,000 \mathrm{~m} \mu$. In saturated HCl there was no change in color indicating the formation of a new band such as those characterizing the sulfonephthalein oxonium salts in concentrated $\mathrm{HCl}$. 


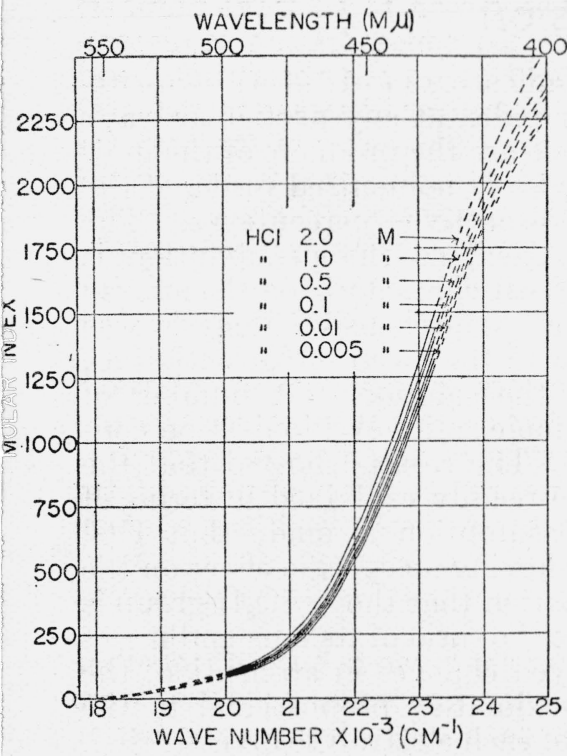

FIGURE 3.-Molar index of solutions of $\beta$-naphthoquinonesulfonic acid in $\mathrm{HCl}$ plotted against wave numbers.

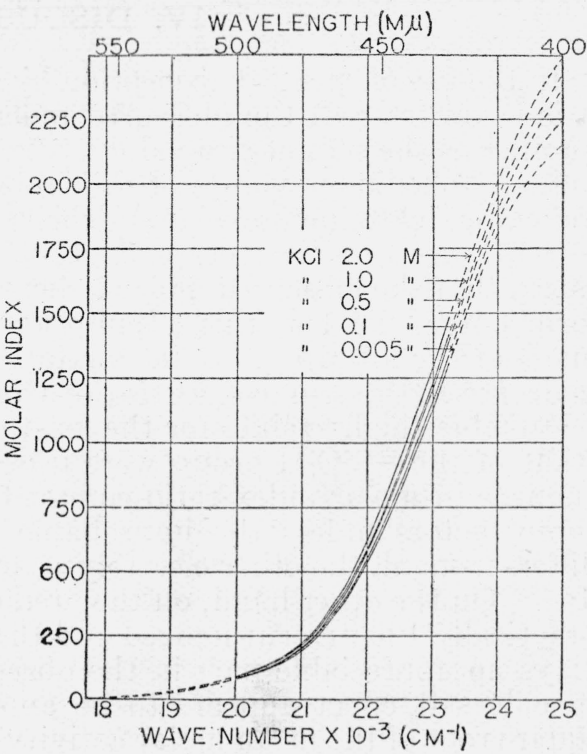

FIGURE 4.-Molar index of solutions of $\beta$-naphthoquinonesulfonic acid in $\mathrm{KCl}$ plotted against wave numbers.

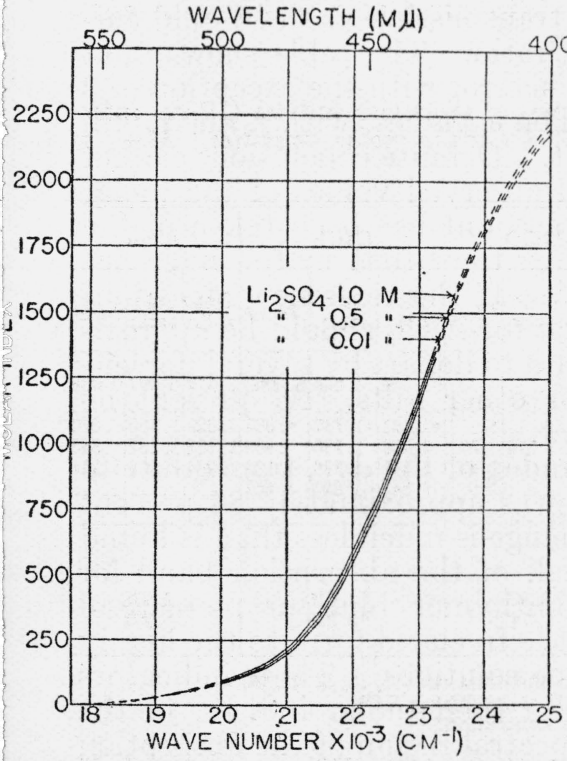

FIGURE 5.-Molar index of solutions of $\beta$-naphthoquinonesulfonic acid in $\mathrm{Li}_{2} \mathrm{SO}_{4}$ plotted against wave numbers.

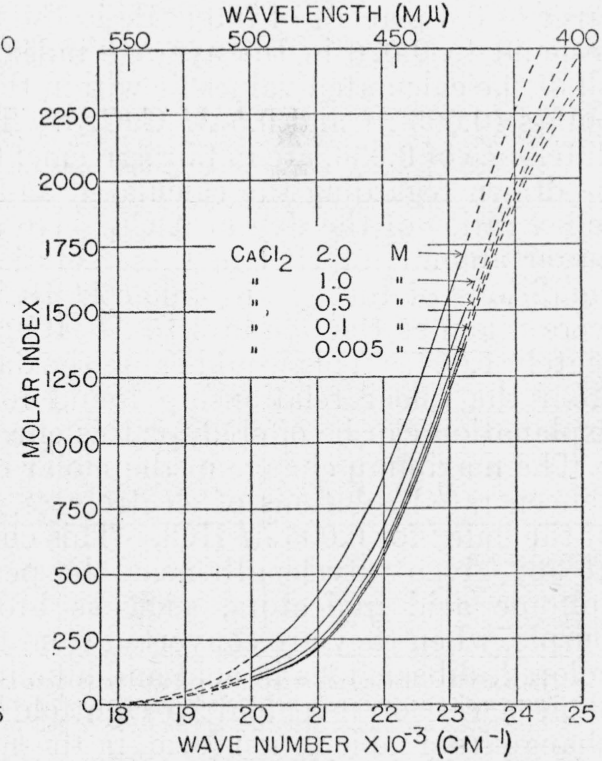

FigURe 6.-Molar index of solutions of $\beta$-naphthoquinonesulfonic acid in $\mathrm{CaCl}_{2}$ plotted against wave numbers. 


\section{DISCUSSION}

In the use of spectral absorption by indicators in $\mathrm{pH}$ measurements, it is usual to treat the measured molar index at any particular wave number as the sum of two values. These are the products of the individual molar index values of the ionized and nonionized forms of the indicator chromophore and their respective percentages. The $-\mathrm{SO}_{3} \mathrm{H}$ group, however, is highly ionized, so the presumption is raised that the measured molar index is that characterizing the ionized form only. To test this assumption a comprehensive analysis was made of the absorption data in relation to the mean molar activities, ionic strength, and concentrations of the solutions. A number of reasonable (high) values for the ion-to-mole ratios and ionization constant of the $-\mathrm{SO}_{3} \mathrm{H}$ group were used. The results showed that the changes in molar index ratio cannot be readily explained in terms of these factors unless the improbable assumption is made that $\mathrm{HCl}$ differs from all the other electrolytes in having no specific effect on the dye. On the other hand, on the predication that the $-\mathrm{SO}_{3} \mathrm{H}$ group is practically 100 percent ionized and that the ratio of its ions and moles plays no appreciable part in the observed changes in absorption, the specific salt effect appears to be approximately proportional to the square root of the mean molar activity of each electrolyte investigated.

The best empirical expression relating the molar index ratio and activity for each electrolyte was found to be $y=a+b x$, where $y$ is the molar index ratio, $x$ is the square root of the activity of the salt or acid, $b$ is the slope of the curve, and $a$ is the molar index ratio at zero salt concentration. In table 1 are given the observed and calculated molar index ratios and the constants for each salt. An experimental error of 0.5 percent of full scale in the transmission values would correspond to 0.026 in the average index ratio. The table shows that all of the calculated values lie within this error with the exception of 2 points $\left(0.005 M\right.$ and $\left.0.5 M \mathrm{CaCl}_{2}\right)$. The $a$ values, with a maximum difference of 0.036 , are in fair agreement. Definite conclusions cannot be drawn regarding the calculated and observed values of the molar index ratios of the dye in $\mathrm{AlCl}_{3}$. No account has been taken of the larger amount of $\mathrm{HCl}$ in these solutions than that in the reference conditions of the dye in $0.005 \mathrm{M} \mathrm{HCl}$. If the reference conditions were taken as the dye in $0.15 \mathrm{M} \mathrm{HCl}, a$ for $\mathrm{AlCl}_{3}$ should be approximately 1.064. This would cause the data to depart by several percent from the linear relationship found for other salts. At present no explanation can be offered for this effect.

The maximum change in the molar index of the dye, from dilute to concentrated solutions of electrolytes, was approximately 84 percent of the index for $0.005 \mathrm{M} \mathrm{HCl}$. This change is much less than is found at any given wavelength near the peak of the absorption band for sulfonic acid indicators, such as bromthymol blue or metacresol purple, when they are converted from the free acid form to the highly colored, dibasic ions in acid and alkaline solutions. These indicators show a rise of sevenfold to eightfold in their molar indices, in the change from mole to ion form, in the spectral region of the absorption band for each indicator in its yellow form. Thus the maximum effect on the absorption by $\beta$-naphthoquinonesulfonic acid is less than 15 percent of the effect of $\mathrm{H}$-ions on the absorption by similar forms of indicators. 
The data show that increase in absorption by the dye is the direct physical result of the presence of increasing amounts of strong electrolytes, rather than the result of the effect of the added ions on the ionization of the dye, and is specific for each salt [3]. This is analogous to the specific cationic effect on the light absorption by nitrate ions reported by von Halban and Eisenbrand [26]. The relationship of the molar activity of the solution to the absorption by the dye is consistent with the views held by von Halban and Ebert and others $[1,25]$ that the electrostatic forces between ions may be largely responsible for the observed changes.

Rabinowitch and Epstein [20] have recently shown that the effect of $1 \mathrm{M} \mathrm{KCl}$ on thionine in water is to reduce its absorption index by approximately 20 percent. As shown in table $1,1 \mathrm{M} \mathrm{KCl}$ changes the absorption by about 10 percent in the opposite direction. It is of interest to note that the two compounds being compared were in oppositely charged ionic forms.

It is not unreasonable to presume that the absorption of light by all indicators containing a quinonesulfonate grouping will be altered by a specific salt effect in the presence of an electrolyte. This modification of the absorption may introduce errors in $\mathrm{pH}$ estimations made with indicators when it is assumed that measurements of absorption or hue give directly the $\mathrm{In}^{-} / \mathrm{HIn}$ ratio, which is a function of $\mathrm{pH}$. If the specific salt effect has the same magnitude for the $\mathrm{In}^{-}$and HIn or other [6] forms of the indicator involved in eq 1, the resulting compensation leaves the $\mathrm{pH}$ values unaffected by this factor.

\section{CONCLUSIONS}

1. The absorption index of $\beta$-naphthoquinonesulfonate ion is increased by $\mathrm{HCl}$ and salts in proportion, approximately, to the square root of their activities.

2. Hydrochloric acid acts in the same way as a salt on the absorption of light by the dye.

3 . The molar indices of the $\beta$-naphthoquinonesulfonate ion in solutions of $\mathrm{HCl}$ and salts indicate that the magnitude of the color changes is determined by the specific ions and not by the salt type (uni-uni, uni-di, etc.).

4. The change in the average molar index ratio produced by salts and $\mathrm{HCl}$ in concentrations greater than $0.005 \mathrm{M}$ is primarily a small increase in magnitude without a marked shift in the absorption band. These optical effects may be due mainly to the influence of the adjacent ions and electric field on the electronic structure and resonance of the quinone group.

5 . The evidence of a specific salt effect on the absorbing system of the $\beta$-naphthoquinonesulfonate ion points strongly to the possibility that electrolytes may have a similar effect on all indicators and may introduce errors in $\mathrm{pH}$ measurements in concentrated solutions.

6. It is concluded that the specific effects of ions on the absorption indices of positive, neutral, and negative forms of an indicator should be investigated, as well as the normal effects of the electrolytes on the dissociation of the indicator, for accurate $\mathrm{pH}$ measurements. 
The authors express their appreciation to K. S. Gibson, of the Photometry and Colorimetry Section of the National Bureau of Standards, for advice and the use of the recording spectrophotometer, and to H. J. Keegan of that Section for his cooperation in making the transmittancy measurements.

\section{REFERENCES}

[1] S. F. Acree, Am. Chem. J. 38, 1 (1907); 39, 528 (1908); 41, 483 (1909); 48, 372 (1912); 49, 347 (1913).

[2] R. T. Birge, and S. F. Acree, J. Am. Chem. Soc. 41, 1031 (1919).

[3] C. H. Brightman, J. J. Hopfield, M. R. Meacham, and S. F. Acree, J. Am. Chem. Soc. 40, 1940 (1918); J. Bact. 5, 169 (1920).

[4] W. R. Brode, J. Am. Chem. Soc. 46, 581 (1924); and Chemical Spectroscopy (John Wiley \& Sons, New York, N. Y., 1939).

[5] C. A. Bury, J. Am. Chem. Soc. 57, 2115 (1935).

[6] M. A. Elliot and S. F. Acree, J. Research NBS 23, 675 (1939) RP1263.

[7] O. J. Folin, Biol. Chem. 51, 386 (1922).

[8] K. S. Gibson and H. J. Keegan, J. Opt. Soc. Am. 28, 372 (1938).

[9] A. Hantzsch, Ber. deut. chem. Ges. 39, 1090 (1906).

[10] A. C. Hardy, J. Opt. Soc. Am. 25, 305 (1935) ; 28, 360 (1938).

[11] H. S. Harned and G. A. Akerlof, Physik. Z. 27, 411 (1926).

[12] H. S. Harned and R. E. Ehlers, J. Am. Chem. Soc. 55, 2179 (1923).

[13] H. S. Harned and W. J. Hamer, J. Am. Chem. Soc. 5y, 27 (1935).

[14] I. M. Kolthoff and C. Rosemblum, Acid and Base Indicators, p. 216 (The Macmillan Co., New York, N. Y., 1937).

[15] H. J. Lund, Kg. Danske Videnskab. Selskab, Math-fys. Medd., Sec. 6 (1931).

[16] H. J. Lund, Chem. Soc. II, 1844 (1930).

[17] C. M. Mason, J. Am. Chem. Soc. 60, 1638 (1938).

[18] J. Michaelson, J. Opt. Soc. Am. 28, 365 (1938).

[19] W. Ostwald, Lehrbuch der allegemeinen Chemie, p. 799 (1903); Grundriss der allegemeinen Chemie, 6th ed. p. 462 (Theodor Steinkopff, Dresden and Leipzig, 1920).

[20] E. Rabinowitch and L. F. Epstein, J. Am. Chem. Soc. 63, 69 (1941).

[21] J. Stieglitz, J. Am. Chem. Soc. 25, 1112 (1903).

[22] G. Scatchard, W. J. Hamer, and S. E. Wood, J. Am. Chem. Soc. 60, 3061 (1938).

[23] T. Shedlovsky and D. A. MacInnes, J. Am. Chem. Soc. 58, 1970 (1936); 59, 503 (1937).

[24] A. Thiel and E. Diehl, Sitzber. Ges. Beförder ges. Naturw. Marburg 62, 472 (1927).

[25] H. von Halban and L. Ebert, Z. physik. Chem. 112, 321 (1924).

[26] H. von Halban and J. Eisenbrand, Z. physik. Chem. 132, 401 (1928).

[27] R. Wizinger, Organische Farbstoffe (F. Dümmlus, Berlin, 1933).

Washington, August 5, 1941. 